\title{
PLASTIC CHAIR VERSATILITY AS AN APPROACH TO CONSTRUCT PASAR BARU INFORMAL SPACE
}

\author{
Roland Tejo Prayitno ${ }^{1 *}$, Yandi Andri Yatmo ${ }^{2}$ Paramita Atmodiwirjo $^{2}$ \\ ${ }^{1}$ Graduate Student, Department of Architecure, Universitas Indonesia, Kampus Baru UI, Depok 16424, Indonesia \\ ${ }^{2}$ Department of Architecture, Universitas Indonesia, Kampus Baru UI, Depok 16424, Indonesia \\ *Corresponding author; Email: rolandtejoprayitno@gmail.com
}

\begin{abstract}
This paper investigates materiality as architecture manifestation in commercial informal space. The materiality approach in this paper revolves around the Manuel De Landa idea of material's properties and capacity, which interact to each other to create unlimited possibilities. This cycle of interaction is what Manuel DeLanda called as morphogenic power of its own. Understanding material system and existing context are two essential process in order to produce a responsive design in this random, unpredictable pattern of informal space, which in this paper, the context that will be specifically studied is Pasar Baru. In the further study, the material which will be studied along with Pasar Baru context is the versatile usage of plastic chair. This paper will investigate materiality approach as a relevant method to create a contextual design, as this approach will be highly based on interaction system between the physical material and the context.
\end{abstract}

Keywords: Materiality; morphogenic power of its own; informal space.

\section{INTRODUCTION}

In this paper I would like to discuss about materiality in informal space. The informal space I would like to discuss here is specifically the commercial one. In Indonesia, informal space is considered as a problematic space, yet contains a big potential. No certain order, vendor's behavior (littering, vandalism), are one of the cases that might cause problem in the informal space. Relatively low rental cost (usually only by paying "security fee" to the local operator), makes informal space become the first choice for low class economy vendor. Aside from the problems it may cause, this informal space also holds an opportunity to produce new discussion in architecture. The randomness, unpredictable context development in this informal space could bring a new perspective in architectural design method. It is very important to understand specific existing context and its potential in order to produce a design that is responsive to the social situation. The site I would like to study specifically in this paper is Pasar Baru in Jakarta, Indonesia.

The next question we might have here is, why material approach? First, we need to understand what is material. Material here is not only substances to execute architectural concept, to create certain impression in one space, but rather a system of how those substances interact each other in order to make the bigger substances (in this case, space) it created works in certain way. DeLanda mentioned two principal elements that works in one substance: property and capacity (DeLanda, 2015), which I will discuss further these two elements in the next section. Shortly, these two elements work simultaneously to affect or to be affected (causality) with other substances. This causality is what then, construct possibility of spaces, whereas these spaces, as DeLanda mentioned, is self-generated as the impact of interaction between the substance with the context which the substance placed into (DeLanda, 2015). Here I see the pattern of how possibility of spaces constructed is relevant with the randomness and unpredictable development of this informal space has.

The next question I would like to state here is how materiality contribute to construct urban space? What is the relation between materiality and urban space? Burchardt and Hohne once stated that city is constructed by material assemblage and diverse human population. They stated that material, as an infrastructure, mediate social relation, and this materiality and diversity interact each other to build each other (Burchardt and Hohne, 2015). In this view, we can see a material as a mediator that connect the substance of the object into the physical world. Material, with every materiality contained, is what directly interacts with other components, and the materiality in the material will surely highly influence the interaction. Furthermore, this materiality will create certain system of relationship, whereas this system plays important role to define how the interaction will occur between context and the architecture.

Back to the existing context, the location I would to discuss in this paper is Pasar Baru, specifically the main street where the main commercial activities are. The main street of Pasar 
Baru is usually used for a shortcut from Samanhudi street to reach busway station or other public transportation around Juanda street and Post street. The main user of this Pasar Baru main street is not only people who want to shop at Pasar Baru, but also people from offices at Samanhudi street. Therefore, the peak activities of the informal are around the after-work hours. This informal space at Pasar Baru and its potential, will be the basis of the design, along with the materiality approach.

\section{MORPHOGENIC POWER OF ITS OWN}

As mentioned before, DeLanda mentioned two main elements of materiality: property and capacity. Property is the condition of the substance, and capacity is how this material work. These two elements work simultaneously to interact with the existing context, in which DeLanda called this interaction as causality (DeLanda, 2015). This causality interaction has two types, based on the possibility it creates: linear and non-linear causality. Linear causality talks about a rigid formula of how the material respond with the context given. The possibility it creates is relatively predictable, since the interaction can already be calculated from the rigid formula. Nonlinear causality, on the other hand, has no rigid formula. One same material could produce different possibility with the context given. The result of the interaction here become relatively unpredictable, and generate unlimited possibilities (DeLanda, 2015). This second type is more relevant with what we discuss here, because the context we are going to discuss in this paper is informal space, where which we have discussed before, that this space contains randomness, unpredictable elements, that generated from its social situation.

Understanding the existing context and the material system become two most important things in this paper. How certain system of material placed in the certain context, then interact, and generate unlimited possibilities to the creation of spaces. What I would like to demonstrate in this research through design (Till, 2012), is how the property and capacity interact with the existing context, creating further level of material system, that interact with the context, which this context influenced by the material system, to create further interaction to each other again, and so on so forth. These self-generate cycle of interaction between materiality and existing context is what DeLanda called "morphogenic power of its own" (DeLanda, 2015), which generate unlimited possibilities to the creation of spaces. The word "morphogenic" comes from biology term, which means the development of structural features of an organism or part. This term shows how the materiality work, that is as a possibility which generated, interact, and develop along with the local context. The materiality here is not only a supporting substance, but now it become the main system which mainly based on the possibilities of how the architecture work and operate. Material approach become even more relevant now because the architecture it created is constructed based on the interaction with the unpredictable, random local context. The architecture here will be continuously adjusting with the development of the existing context, since both develop simultaneously as this development is the impact of the interaction to each other.

\section{INFORMAL SPACE AT PASAR BARU}

As stated before, the location we are going to discuss in this paper is the main street of Pasar Baru. In this section I would like to discuss further about the urban furniture from the informal space. As we discuss earlier that material works as a mediator, we must then carefully pay attention to the objects that construct the informal space, as the materiality of these objects will determine the interaction with the context. In this paper, I will specifically study the urban furniture, as these urban furnitures are the main component that shapes the informal space and create interaction with the context. Furthermore, I would like to specifically focus on one material from these urban furnitures, and that is the plastic chair. The question then, why plastic chair? As one of the materials in Pasar Baru urban furniture, plastic chair has interesting materiality. The materiality here is about how this material as a substance, contributes to construct the bigger substance, which in this case is the urban furniture. The materiality of plastic chair in Pasar Baru has a rich interaction with the surrounding context, both contexts as in Pasar Baru context, and urban furniture context. Further explanation regarding the plastic chair materiality will be explained in methodology section.

The next question is, what is the specific context in Pasar Baru? What makes Pasar Baru different from other similar outdoor informal shopping area? Before answering these questions, I would like to make a comparison between Pasar Baru and other outdoor informal shopping area. The comparison I took are Kota Tua and Sabang street in Jakarta, which also known as an outdoor recreational area that contains informal activity as one of the main activities. As we can see in Figure 1, Pasar Baru has an overlap time frame activity between the formal and informal shops. Kota Tua does have this overlap 

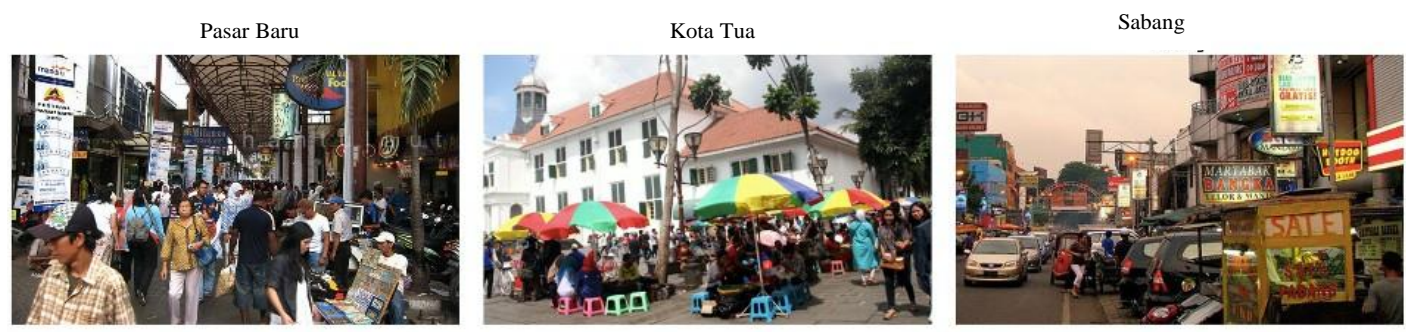

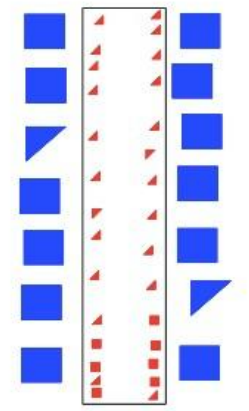

Formal-informal interaction

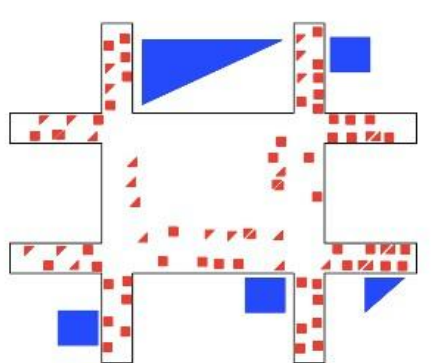

Informal domination

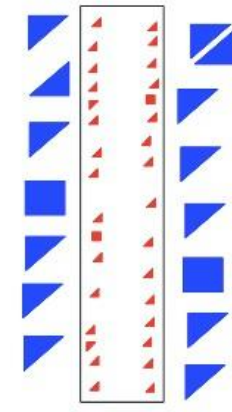

Shifted subject

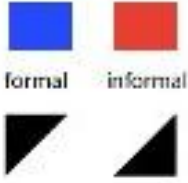

day

night

Fig. 1. Outdoor Informal Shopping Area Comparison

as well, we can see that Kota Tua has more dominance in informal activities than the formal one, unlike Pasar Baru, that has a relatively balanced intensity of the informal and formal shops. Sabang street has a relatively balanced intensity between formal and informal shops, but as we can see, there is almost no overlap time frame between formal and informal shops. Most formal shops open at day and close at night, and on the other hand the informal operates the opposite. It is as if the shops in Sabang has two different shops at day and night.

From here I will conclude that Pasar Baru has this interaction between the formal and informal, which I see the urban furniture plays important role in this interaction.

\section{METHODOLOGY}

The investigation started from drifting tracing method (Corner, 1999), and documented the existing by using montage. This montage was used to understand how this urban furniture works in Pasar Baru context. We can see the montage in Figure 2. In these collections of montage in Figure 2, I want to show four information, each shown in strip. The first strip shows the montage as it is in the existing, the second strip shows informal shops operational time frame, the third emphasize how the plastic chair being used in the urban furniture, and the forth shows materiality category of the plastic chair. As we can see in the montage in Figure 2 first strip, there are various material used for this urban furniture to construct the informal space. And in the third strip, it is shown that in this informal space in Pasar Baru, plastic chair is being used quite often and also intriguing. Plastic chair has unconventional interaction than what is commonly known. Plastic chair here is not only understood as a tool for people to sit, but also as a height adjuster to show one product, a socialization mediator, and as a language. For short, I call these three categories as leveling, socialization and restriction

Plastic chair as leveling is used for the shop to show the products visually more attracting and convenient to the passer by. There are two types of leveling: leveling the whole display like in the first image in the montage, and leveling one product to show one sample of product, as we can see in Figure 3. Plastic chair as socialization is when the plastic chair became a tool to generate a conversation. A merchant sits in front of the formal shop and talk to another fellow merchant, or an after-work employee sit and grab some food in certain food street vendor while having a small chat with the merchant. In some cases, the plastic chair as socialization are being used to advertise certain product from the sponsor. The hole between the chair's leg is filled with advertisement from the sponsor. Plastic chair as a restriction, create a language between the formal and informal shops. A placement of one or two plastic chair, and sometimes along with potted plan, in front of the formal shop will be understood by the informal shops to not open the stand in front of the shop. 

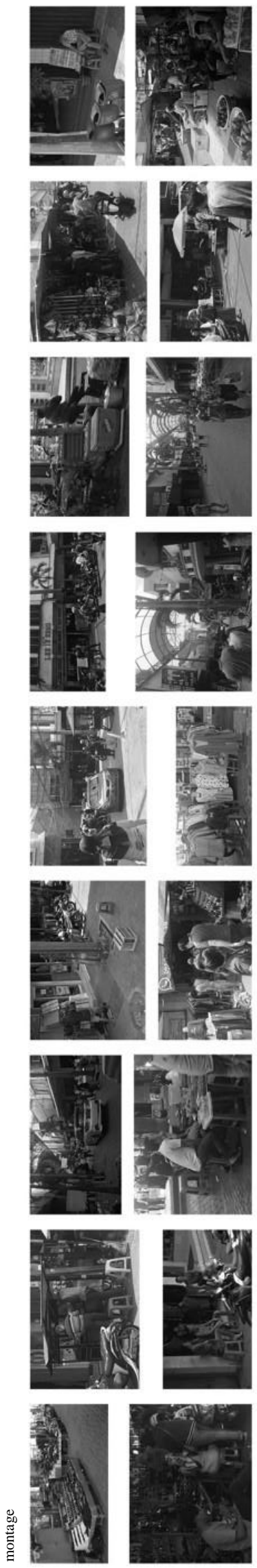
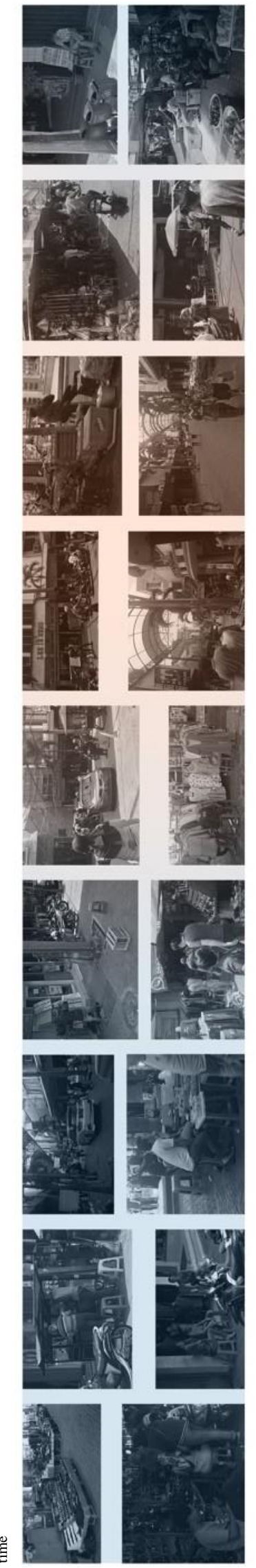
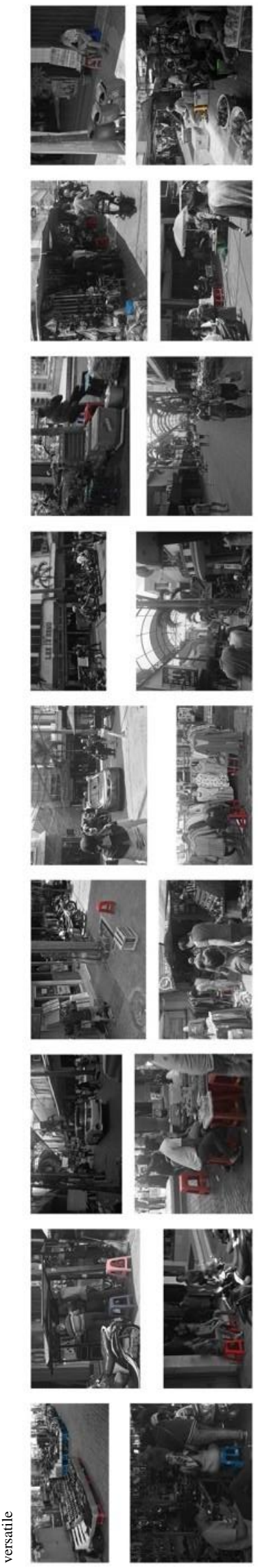
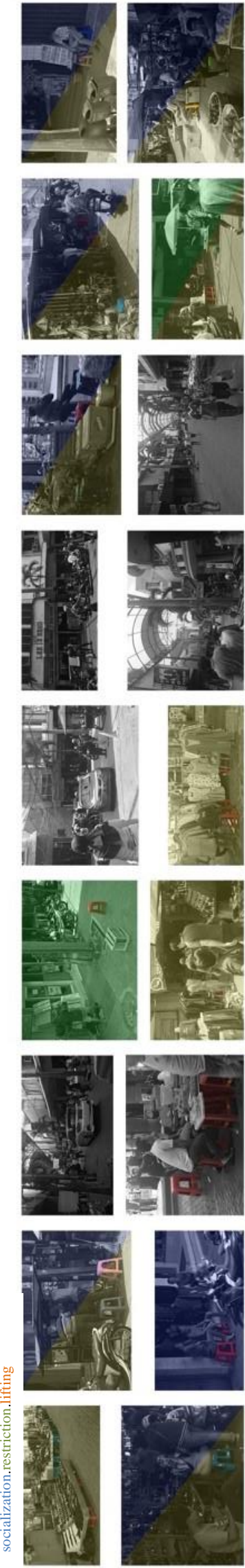

Fig. 2. Montage 

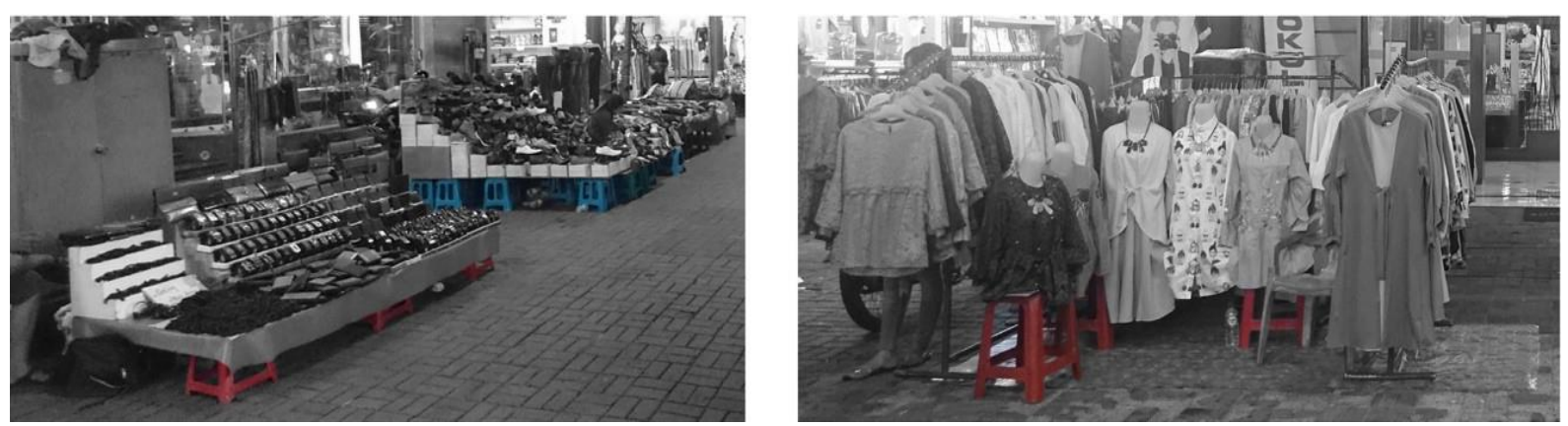

Fig. 3. Plastic Chair Leveling

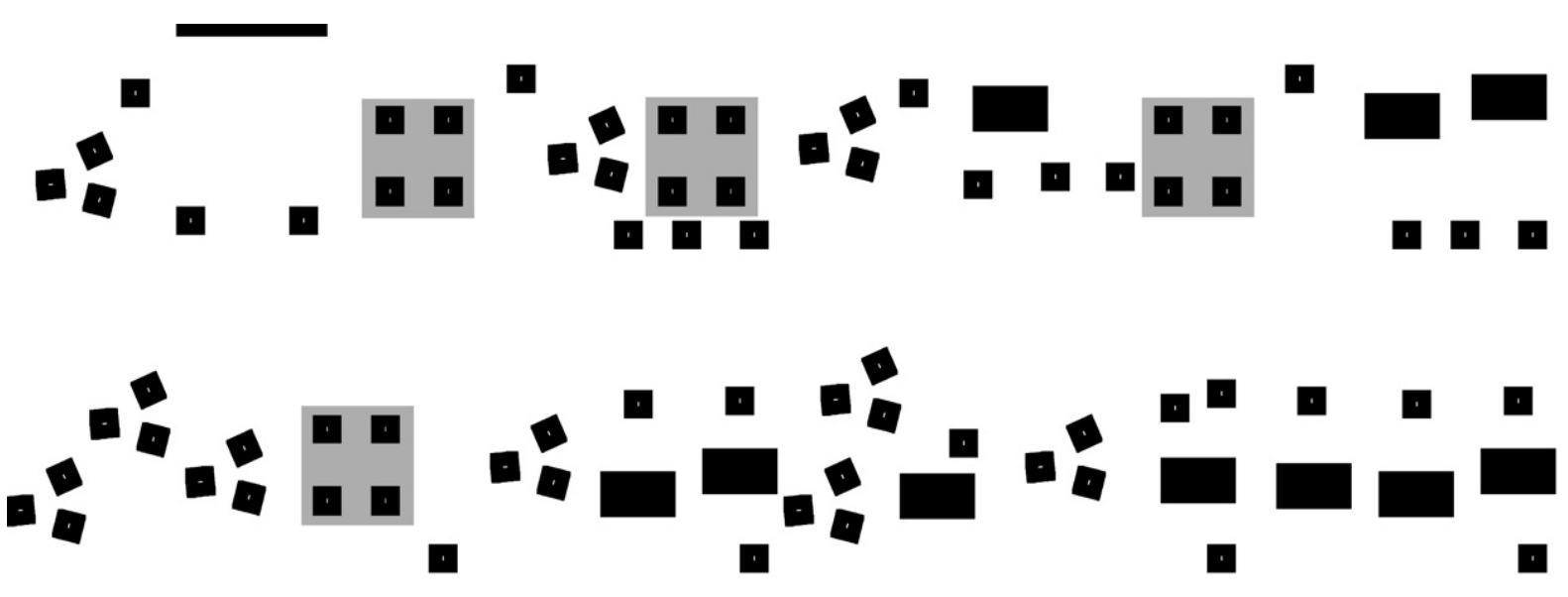

Fig. 4. Nolli Map of Plastic Chair in Pasar Baru Main Street

After understanding how this plastic chair is specifically being used in certain Pasar Baru's informal urban furniture, I proceed the study to the macro system of this plastic chair. How this plastic chair usage distributed throughout Pasar Baru main street. To see this distribution, I traced the placement of plastic chair by using Giambattista Nolli method by showing solid void area of a city. In Figure 4, I showed the solid void of the plastic chair in Pasar Baru main street to see the distribution pattern.

As we can see in Figure 4, there are repeating pattern, where one kind of usage of the plastic chair will make certain configuration, which will be repeated in other area that using similar usage. Here I interpret the pattern as dynamic grid, which the pattern repeats not in static way in every day, but instead keep changing and shifting every night depend on the situation. This situation could be the operational day of the formal shops, the local big day (as Pasar Baru is known as quarter for Chinese Indonesian and Indian), etc. This what makes the face of Pasar Baru is different every night, as the configuration of the informal shops keep changing and shifting every night. Here then, I will conclude the dynamic grid as the main material system of the plastic chair in Pasar Baru.

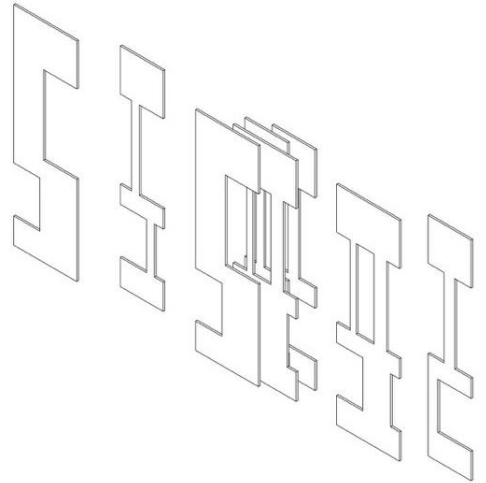

Fig. 5. Layered Dynamic Grid Visualization as Material System

The dynamic grid here I understood as a dynamic layer, whereas these layers generate interaction between the plastic chair and Pasar Baru as the context. In the design phase, I interpret these layers as a surface, which then became a wall that interact. This wall interaction is based on plastic chair contribution in Pasar Baru urban furniture as leveling, socialization, and restriction. In the further application, I wouldn't limit the interaction between the wall and the context to those three contributions, as in the existing, the plastic chair wasn't limited to the conventional interaction, which is as a tool to sit. 

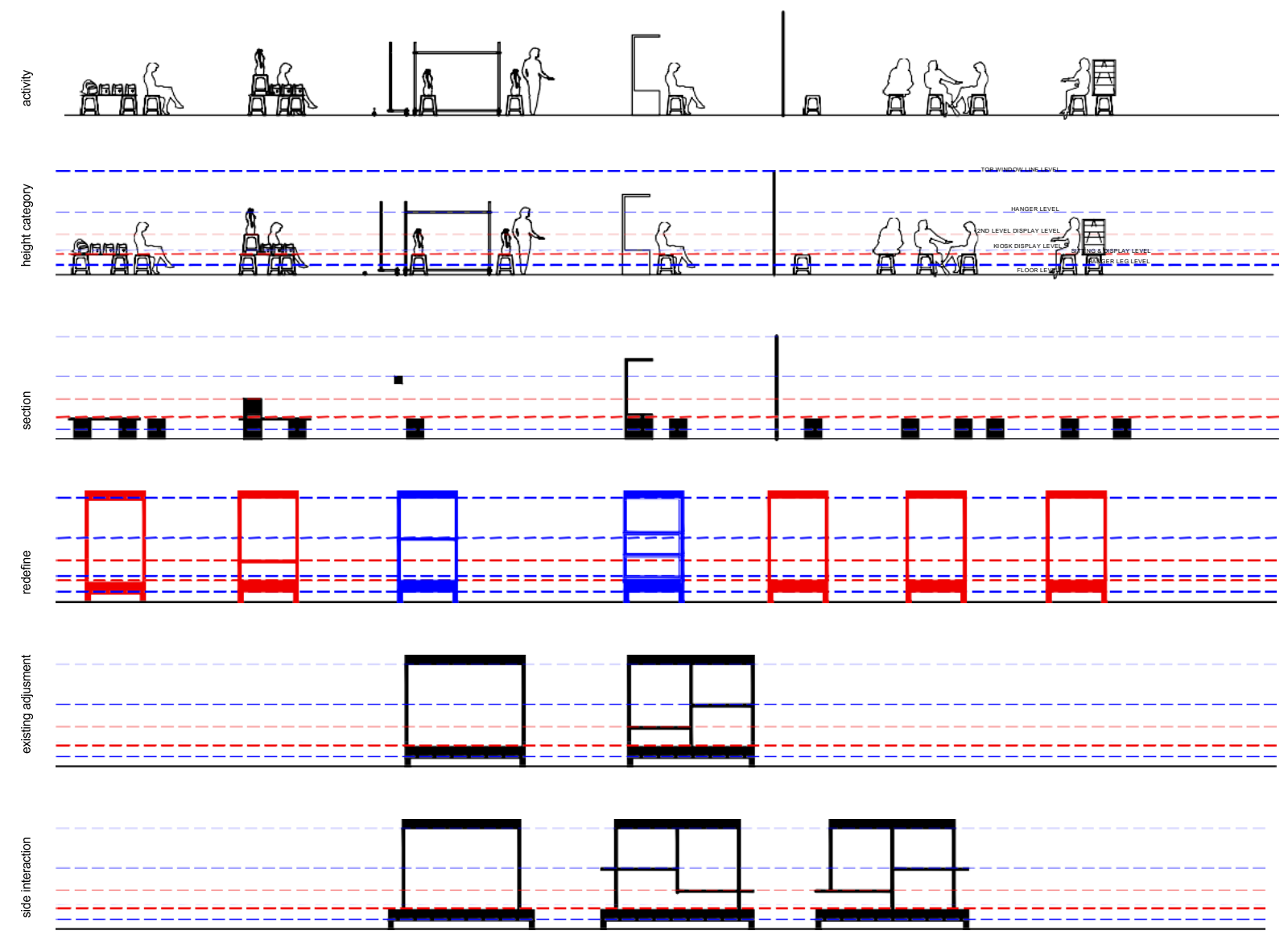

Fig. 6. Section Approach in Layered Walls

These three contributions are like the starting point to generate further contribution and interaction.

The next question here is, how these layered walls interact with the context? Here I used a section approach of how the plastic chair used in daily activity. As we can see in Figure 5, I traced the usage of plastic chair to determine the solid void pattern of the wall. This solid void pattern is what generate the interaction between walls, and also between the wall and the context, as we can see the application of the wall configuration simulated in Figure 6. Every element of from the wall induce further interaction with the user. For example, the height of the lowest level in solid-void pattern on the wall was set in plastic chair level, therefore it could be used as sitting, or if combined with cheap plywood and another wall, could also become a product display for vendor. The lines above could be used to hang a potted plant and work as a language to communicate the formal shop front is restricted to be used for street vendor, or many other interactions. This configuration became the urban language (Dickinson and Giorgia, 2016) for the interaction between formal shop, informal shop, and the passerby and visitor of Pasar Baru.

\section{RESULTS AND DISCUSSION}

The demonstration of the materiality here as the understanding of Jacques Herzog of poetic material (Herzog, 1988). The material may not represent the original material, but processed and treated in certain way that the original form is no longer able to be identified. But the essence of the material, the materiality of the material itself is kept, and manifested in the architecture product.

As stated before, the design in this paper aim to generate this interaction between the architecture and the existing context. The configurations in Figure 8, are only few scenarios and possibilities from what the layered walls could form with the existing context, but the application of the walls could be so much with the context at certain time. Even in one configuration bigger and unlimited, depending on the interaction of walls could generate unlimited variants, depend on the understanding and the need of the variants is what DeLanda call "morphogenic power user. This unlimited possibilities of configuration and of its own". In certain phase, the architecture will develop by itself along with the existing context. In this phase, the architecture development become unpredictable, selfgenerate, adjusting with the existing context. 

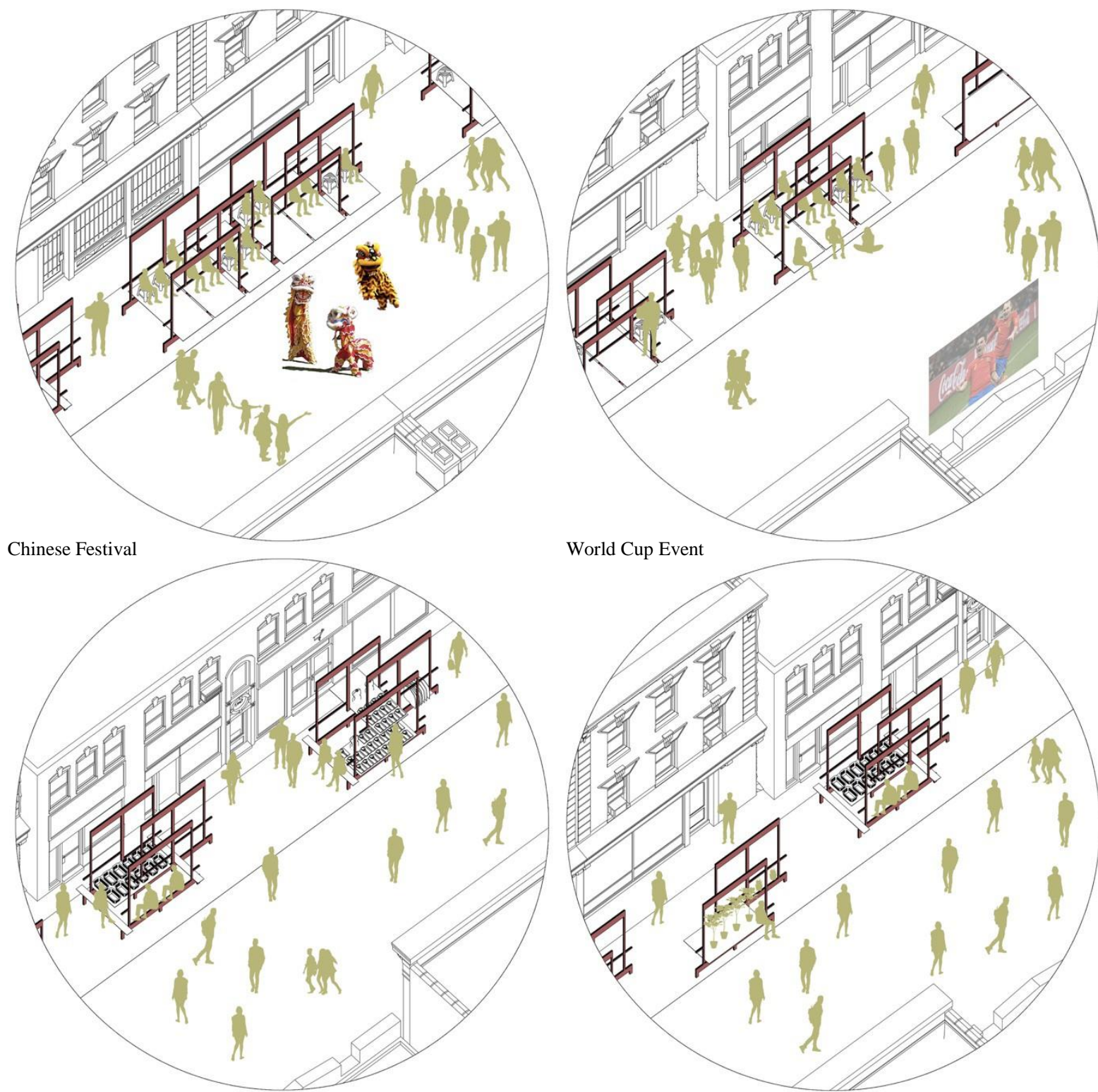

Food Street Vendor and Cloth Street Vendor

World Cup Event

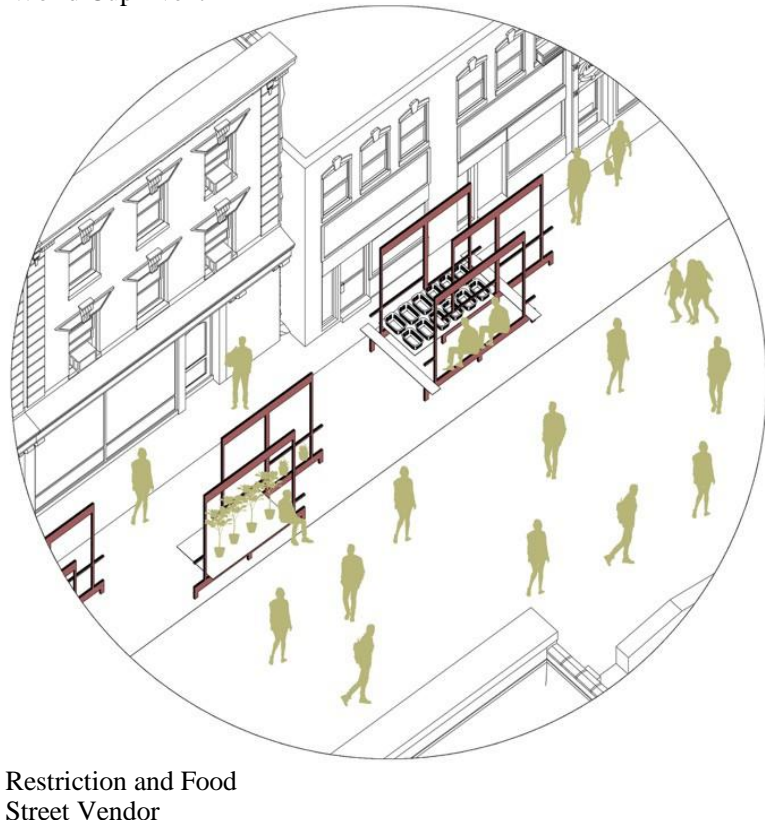

Fig. 7. Layered Wall Simulation

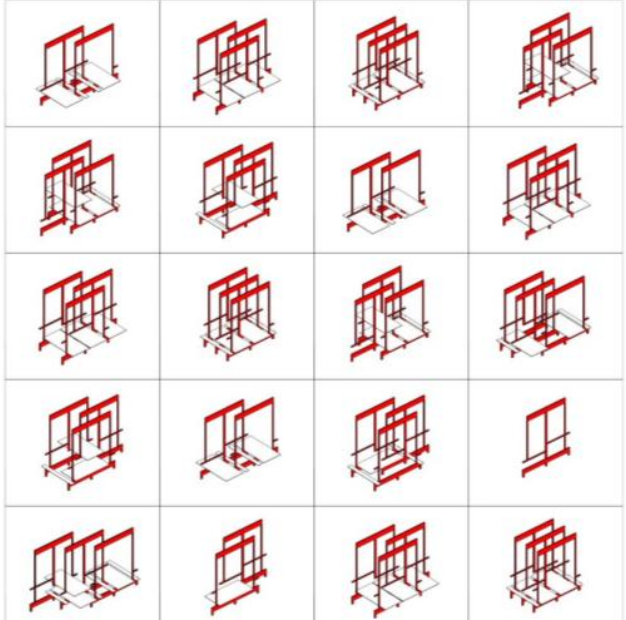

Fig. 8. Configurations and its Variants Simulation

\section{CONCLUSION}

In this investigation, I find the relation and the impact of materiality to the urban space. Material, as a mediator that connects the context to the physical world, has a big influence to the interaction occurred in everyday activities. As we can see, the materiality of plastic chair with its versatility, tried to responding the dynamic context in Pasar Baru's informal space.

In this materiality approach, we can see that certain material will have a specific materiality that only happen and work on specific site context. The same material will have different materiality in another place, and therefore it is very important to understand the context and context-based material system in order to produce a responsive design. In this 


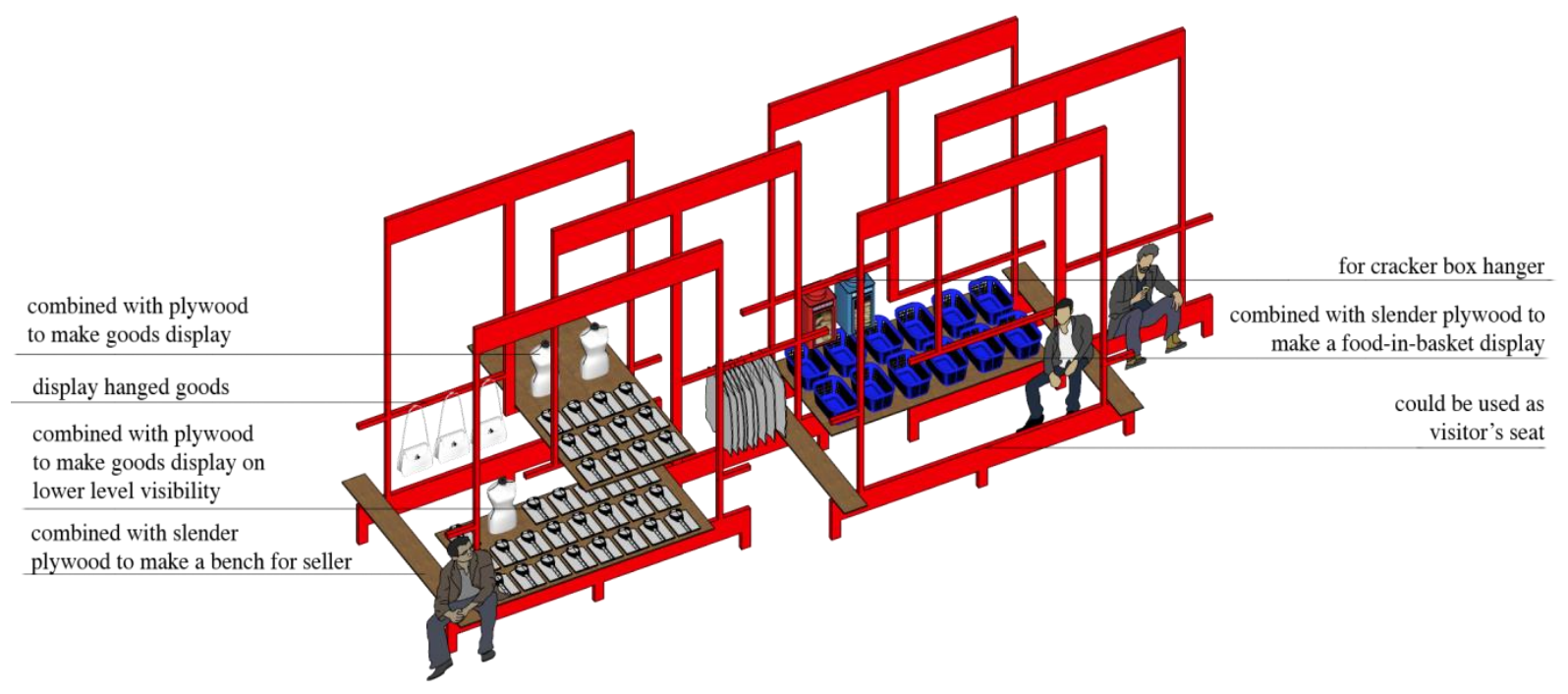

Fig. 9. Wall Simulation, Interaction with the Goods, Merchant, and Visitor

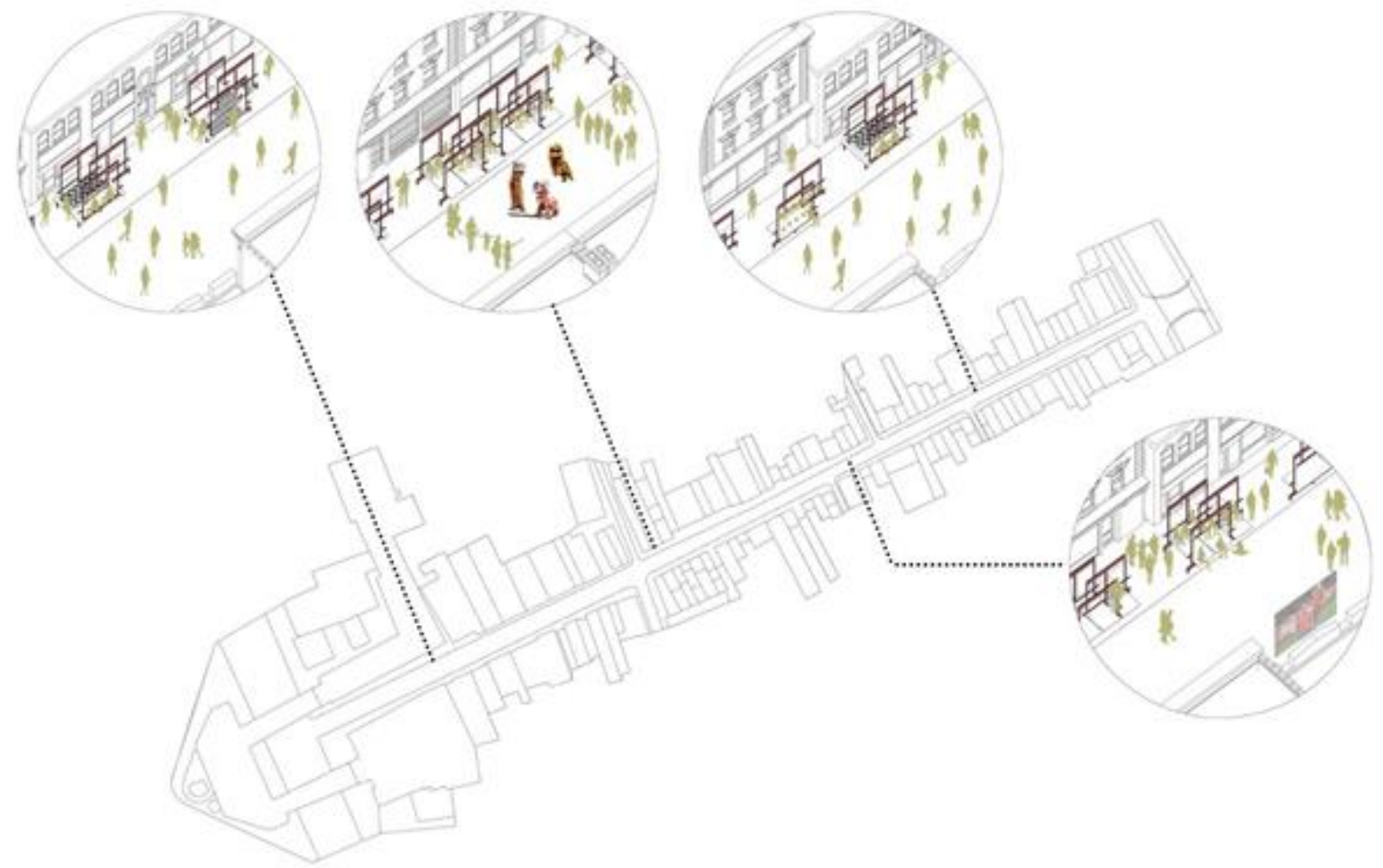

Fig. 10. Scenario Placed in the Context

Pasar Baru case, I found plastic chair materiality in the context as the approach to create architecture that is versatile, dynamic, self-generate in order to accommodate a keep-changing, random pattern in this informal space. I see this materiality approach will give relevant solution, as this approach comes from the interaction between the material and the context. This paper shows an example of one of many materialities system in Pasar Baru that translated into architecture to create relevant interaction with the context.

\section{REFERENCES}

Burchardt, M., and Hohne, S. (2015). New Diversities, 17(2). The Infrastructure of Diversity: Materiality and Culture in Urban Space-An Introduction.

Corner, J. (1999). The Agency of Mapping: Speculation, Critique and Invention. (D. Cosgrove, Ed.) Mappings, 213-252. DeLanda, M. (2015). The New Materiality. Retrieved from Researchgate: https://www.researchgate.net/publication/281672593 
Dickinson, G., and Giorgia, A. (2016). International Journal of Communication. Being Through There Matters: Materiality, Bodies, and Movement in Urban Communication Research, 12941308.
Herzog, J. (1988). The Hidden Geometry of Nature. Till, J. (2012). The 4th International Meeting on Architectural and Urbanism Research. Is Doing Architecture Doing Research? 